\title{
Ethylene Polymerization over Transition Metal Supported Catalysts. III. Vanadium
}

Inês Matos, ${ }^{1}$ Yingjun Zhang, ${ }^{2}$ Isabel Fonseca, ${ }^{3}$ Francisco Lemos, ${ }^{2 *}$ MANDA Lemos, ${ }^{2}$ Filipe Freire, ${ }^{2}$ Anabela C. Fernandes, ${ }^{1}$ Ana M. Botelho do Rego, ${ }^{4}$ Anabela Valente, ${ }^{5}$ João F. Mano, ${ }^{6}$ Rui T. Henriques, ${ }^{7}$ Maria M. Marques ${ }^{1^{*}}$

1 Centro de Química Estrutural, Instituto Superior Técnico, Departamento de Engenharia Química, Av. Rovisco Pais, 1049-001 Lisboa, Portugal. E-mail: pci011@mail.ist.utl.pt

2 Instituto de Biotecnologia e Química Fina, Instituto Superior Técnico, Departamento de Engenharia Química, Av. Rovisco Pais, 1049-001 Lisboa, Portugal. E-mail: flemos@alfa.ist.utl.pt

${ }^{3}$ Departamento de Química, C.Q.F.B., Universidade Nova de Lisboa, Faculdade de Ciências e Tecnologia. 2825-114 Caparica, Portugal. E-mail: iss@dq.fct.unl.pt

${ }^{4}$ Centro de Química Física Molecular, Instituto Superior Técnico, Departamento de Engenharia Química, Av. Rovisco Pais, 1049-001 Lisboa, Portugal. E-mail: amrego@ist.utl.pt

${ }^{5}$ Departamento de Química, Universidade de Aveiro. E-mail: avalente@dq.ua.pt

6 Department of Polymer Engineering, 3B's Research Group, University of Minho, Campus de Gualtar, 4710-057 Braga, Portugal. E-mail: jmano@dep.uminho.pt

7 Departamento de Engenharia Química, Instituto Superior Técnico, Av. Rovisco Pais, 1049-001 Lisboa, Portugal. E-mail: rth@ist.utl.pt

(Received; 29 September, 2006; published: 8 December, 2006)

\begin{abstract}
The polymerization of ethylene in the presence of vanadium catalysts supported on zeolite NaY, HY and charcoal was examined. The catalysts were prepared by the incipient wetness method and characterized by a variety of techniques to determine the oxidation state of the vanadium species inside the zeolite. In all the catalysts that were prepared vanadium is not in a single oxidation state. These catalysts were active in the polymerization of ethylene with activities of the order of magnitude $105 \mathrm{gPE} / \mathrm{molV}$.[M].h for the zeolite catalysts and 103 $\mathrm{gPE} / \mathrm{molV}$.[M].h for the charcoal systems. No polymer could be obtained in the absence of alkylaluminum or aluminoxane in the experimental conditions used. The kinetics of ethylene polymerization reactions using the vanadium catalysts was studied. A kinetic model based on a proposed mechanism for these reactions was used to fit the experimental data. The application of this model resulted in very good fittings and the kinetic rate constants of each elementary step could be estimated. Since the polyethylene that was produced is closely bound to the zeolite catalysts, the thermal and mechanical properties of the PE/zeolite composites were measured, indicating that the presence of zeolite improved the mechanical properties of the polymers produced.

Key Words: Ethylene Polymerization, Transition Metals, Zeolites, Vanadium.
\end{abstract}

\section{Introduction}

Since Hogan and Banks discovery, by the early 50's, that chromium oxide supported on a silicate was able to catalyze the polymerization of olefins to high molecular 
weight polymers [1] a lot of work has been published on related subjects, not only on chromium-based catalysts [2-8] but also on the activity and structure of other supported transition metals [9-17]. Silica, alumina and zeolites have been used as supports [17, 18].

The use of zeolites as catalyst supports for the production of polyethylene has the drawback that results from the fact that the zeolite particles will be embedded in the polymer produced and their separation is difficult. However, many polyethylene applications require additional mechanical strength and various materials have been used to improve mechanical properties [19-25].

In this paper we report the activity and kinetics of vanadium supported on $\mathrm{Y}$ zeolite and charcoal for ethylene polymerization. The results are compared with those of $\mathrm{Cr}$ supported catalysts [26, 27]. The effect of temperature on the kinetic parameters is also studied in the case of these $V$ catalysts and an estimation of the activation energy of each reaction step is depicted. The mechanical properties of the polymer produced was also measured and compared with pure polyethylene.

\section{Results and discussion}

\section{XPS and ESR}

The catalysts $\mathrm{V} / \mathrm{Y}_{\mathbf{1}}-\mathbf{3 . 1}, \mathrm{V} / \mathrm{Y}_{\mathbf{2}}-\mathbf{0 . 4}, \mathrm{V} / \mathrm{Y}_{\mathbf{2}}-\mathbf{2 . 5}$ and $\mathrm{V} / \mathrm{C}-\mathbf{4} .0$ prepared as described in the experimental part were studied by XPS spectroscopy. Figures 1 to 3 and 5 show the XPS spectrum of the samples displaying the $V 2 p_{3 / 2}$ peak. The $V$ peaks lie on the region of the satellites of the oxygen and were obtained by subtraction of those satellites. Thus, it is possible that part of them have been cut by this operation. This seems to be especially true for the peak corresponding to V2 $p_{1 / 2}$, which is not shown for this reason. After peak fitting of sample $V / Y_{1}-3.1$ spectrum (Figure 1), the three values for the binding energy obtained, $\mathrm{BE}=518.0 \pm 0.2 \mathrm{eV}, \mathrm{BE}=516.5 \pm 0.2 \mathrm{eV}$ and $\mathrm{BE}=514.9 \pm 0.2 \mathrm{eV}(\Delta \mathrm{E} \cong 1.5 \mathrm{eV})$, seem to correspond to $\mathrm{V}^{5+}, \mathrm{V}^{4+}$ and $\mathrm{V}^{3+}$ respectively in spite of the great dispersion of values reported in literature specially for $\mathrm{V}^{4+}$ or $\mathrm{V}^{3+}$ species $[9,28-32]$. The $\mathrm{V}$ concentration determined by this method was found to be $5.3 \mathrm{w} \%$ which is higher than that determined by ICP (3.1 w\%). A similar segregation effect, leading to higher concentrations of metal on the surface than in the bulk of the particles, has already been previously observed on catalysts with either $\mathrm{Cr}$ [26] or Pt [33] supported on a zeolite catalyst. The distribution of vanadium oxidation states present on the surface of these sample is $38.5 \%$ for $\mathrm{V}^{5+}, 43.9 \%$ for $\mathrm{V}^{4+}$ and $17.7 \%$ for $\mathrm{V}^{3+}$ (Table 1$)$.

The XPS spectrum of sample $V / Y_{2}-2.5$ (Figure 2) displays the same three peaks, at binding energy values of $\mathrm{BE}=517.85 \mathrm{eV}, \mathrm{BE}=516.49 \mathrm{eV}$ and $\mathrm{BE}=515.07 \mathrm{eV}$. These values are quite close to those observed in the case of sample $V / Y_{1}-3.1$ thus indicating that the same three $\mathrm{V}$ species $\left(\mathrm{V}^{5+}, \mathrm{V}^{4+}\right.$ and $\left.\mathrm{V}^{3+}\right)$ are present in this sample, and in very similar relative concentrations $\left(21.5 \%\right.$ for $\mathrm{V}^{5+}, 59.8 \%$ for $\mathrm{V}^{4+}$ and $18.6 \%$ for $\mathrm{V}^{3+}$ ). The total $\mathrm{V}$ concentration of $3.9 \mathrm{w} \%$ determined by XPS is also very close to the value determined by the same method for sample $V / Y_{1}-3.1$. 


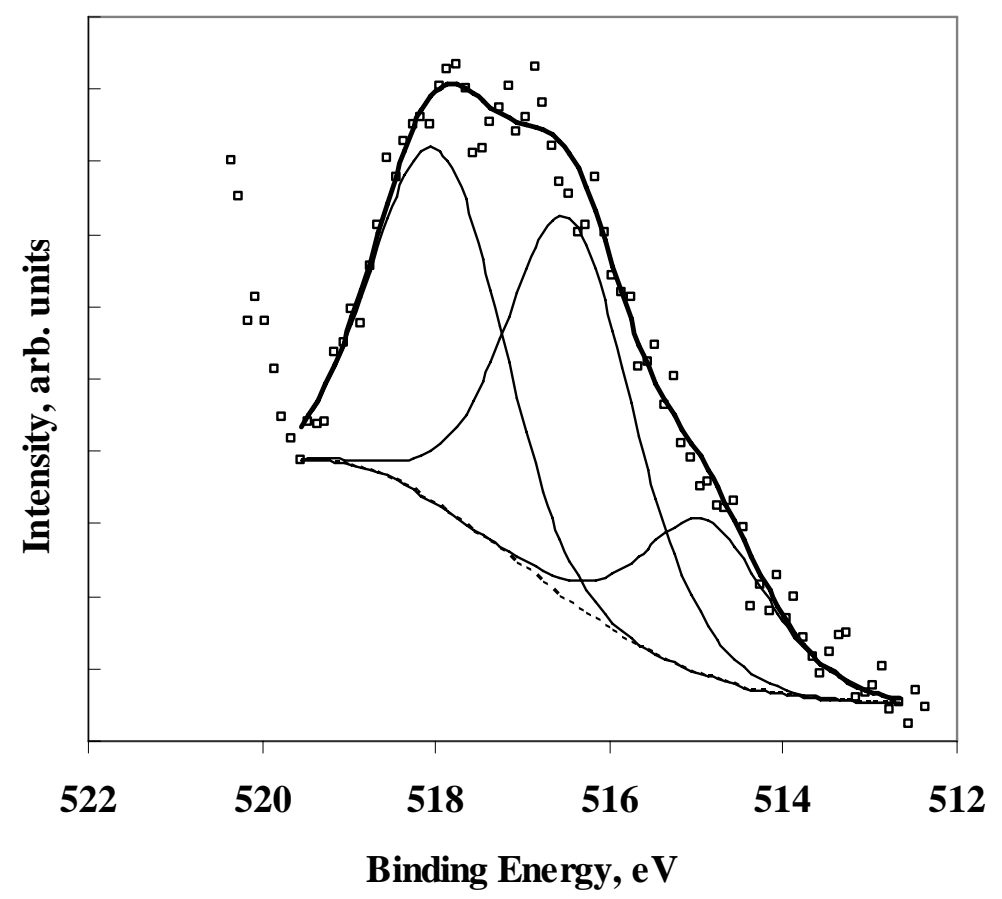

Fig. 1. XPS spectrum of the sample $V / Y_{1}-3.1$ displaying the $V 2 p_{3 / 2}$ peak. After peak fitting the three peaks could be assigned to $\mathrm{V}^{5+}, \mathrm{V}^{+4}$ and $\mathrm{V}^{+3}(\mathrm{BE}=518.0 \pm 0.2 \mathrm{eV}$, $\mathrm{BE}=516.5 \pm 0.2 \mathrm{eV}$ and $\mathrm{BE}=514.9 \pm 0.2 \mathrm{eV}$ ) respectively.

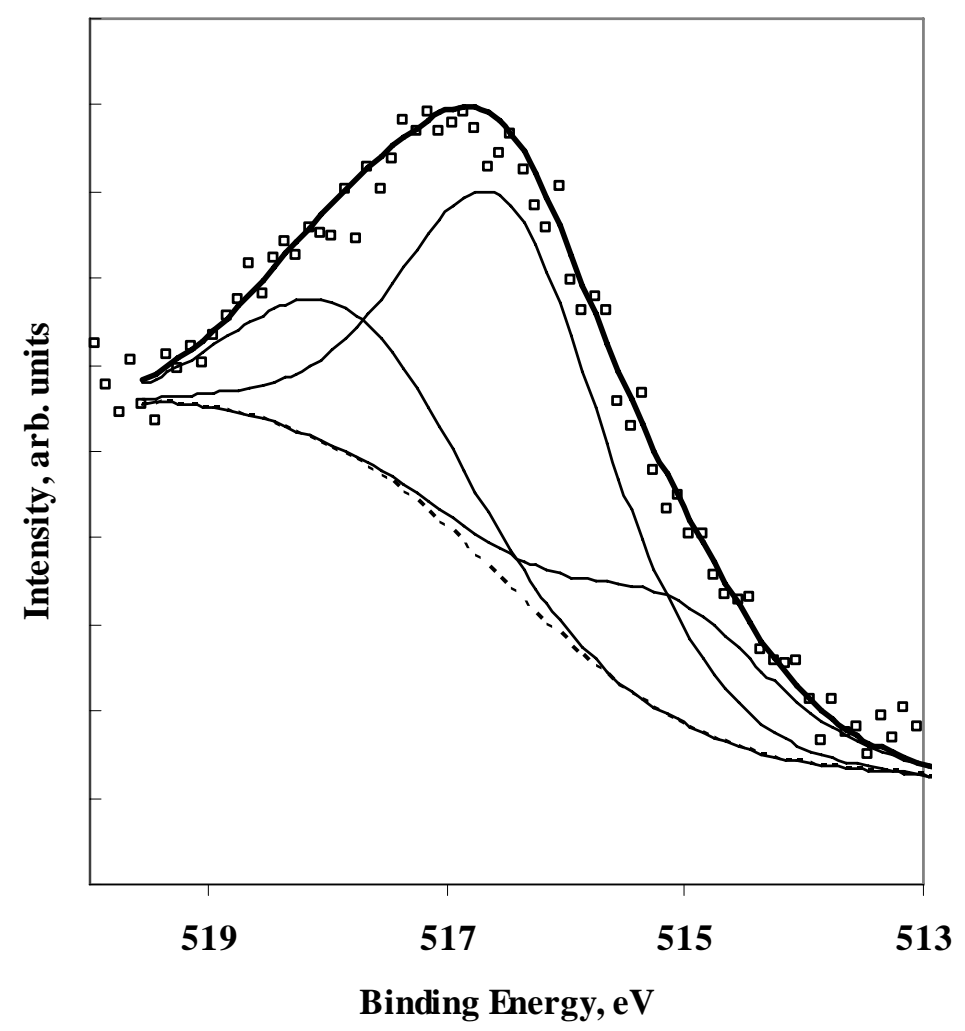

Fig. 2. XPS spectrum of the sample $V / Y_{2}-2.5$ displaying the $V 2 p_{3 / 2}$ peak. After peak fitting the three peaks could be assigned to $\mathrm{V}^{5+}, \mathrm{V}^{+4}$ and $\mathrm{V}^{+3}(\mathrm{BE}=517.9 \pm 0.2 \mathrm{eV}$, $\mathrm{BE}=516.5 \pm 0.2 \mathrm{eV}$ and $\mathrm{BE}=515.1 \pm 0.2 \mathrm{eV}$ ) 
This means that the modification introduced in the support, consisting in the ion exchanging of the cations $\mathrm{Na}^{+}$for $\mathrm{H}^{+}$, does not affect either the oxidation state of the vanadium or the distribution of its different oxidation states.

In the case of sample $V / Y_{2}-\mathbf{0 . 4}$ only two $V$ species could be observed by XPS at binding energies of $\mathrm{BE}=516.0 \mathrm{eV} \pm 0.2$ and $\mathrm{BE}=514.7 \pm 0.2 \mathrm{eV}$ (Figure 3) thus indicating that only $\mathrm{V}^{4+}$ and $\mathrm{V}^{3+}$ species are observed at the surface of this sample. This observation does not rule out the possibility of $\mathrm{V}^{5+}$ being present in the sample, but they should, then, be mainly located on the bottom of pores and consequently will not be seen by this technique. Since it is known that XPS can induce the reduction of vanadium, a fresh sample was later analysed running 50 sweeps one by one in order to compare the successive sums of sweeps. The sum of the first 15 sweeps does not show any difference from the first sweep. The sum of the 50 sweeps displays the increase of the low binding energy side of the $V 2 p$ region showing the reduction induced by the radiation. But, even in the first sweeps, no $\mathrm{V}^{5+}$ could be detected and the species $\mathrm{V}^{3+}$ is already present.

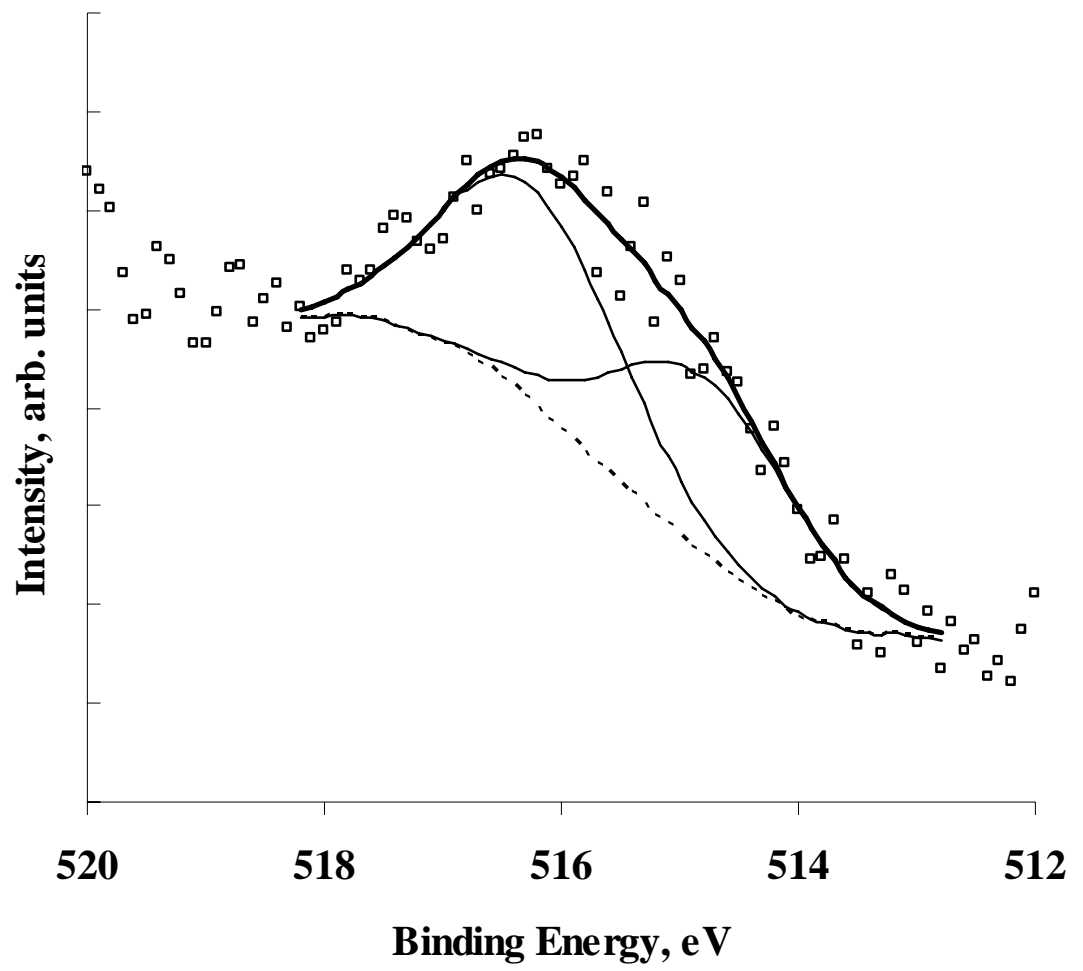

Fig. 3. XPS spectrum of the sample $V / Y_{2}-0.4$ displaying the $V 2 p_{3 / 2}$ peak. After peak fitting the two peaks could be assigned to $\mathrm{V}^{+4}$ and $\mathrm{V}^{+3}(\mathrm{BE}=516.0 \pm 0.2 \mathrm{eV}$ and $\mathrm{BE}=514.7 \pm 0.2 \mathrm{eV}$ )

The main difference between this sample and the previous ones is the much smaller amount of $\mathrm{V}$ present. The surface concentration of $\mathrm{V}$ in this sample is $1.1 \mathrm{w} \%$. The distribution of the different species in this case is $55 \%$ for $\mathrm{V}^{4+}$ species and $45 \%$ for $\mathrm{V}^{3+}$ ones (Table 1).

The ESR study of this sample confirms the presence of $\mathrm{V}^{4+}$ species in the calcined catalyst with a well resolved spectrum (Figure 4), thus supporting the information obtained by XPS. Other authors have found similar behaviours both in alumina and 
ZSM-5 zeolite supported vanadium catalysts $[34,35,36]$. In the first case the alumina is impregnated by using a vanadium (V) salt and after calcination under flowing air at $823 \mathrm{~K}$ reduced species in the final catalyst $[35,36]$. In the second case the vanadium $(\mathrm{V})$ is introduced in the zeolite through a solid-state reaction of the ZSM-5 zeolite with $\mathrm{V}_{2} \mathrm{O}_{5}$ being detected $\mathrm{VO}^{2+}$ species in the reaction product [34].

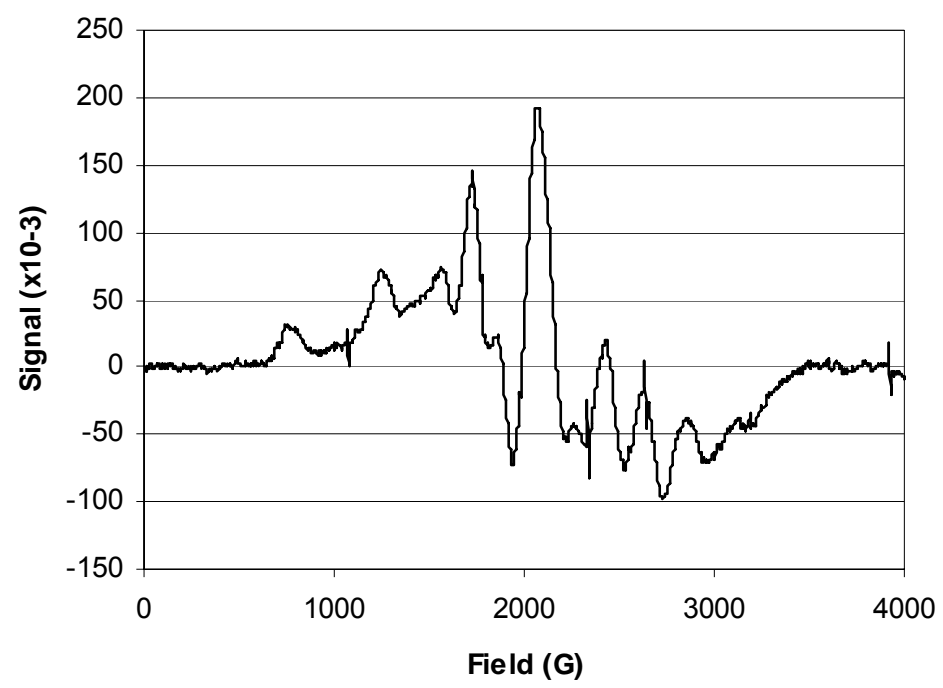

Fig. 4. ESR spectrum of the sample $V / Y_{2}-0.4$ displaying the peaks assigned to $\mathrm{V}^{4+}$ species; $g=2.058$.

The XPS spectrum of the sample VIC-4.0 shows a main peak at a binding energy of $517.0 \mathrm{eV}$ that can be assigned either to $a \mathrm{~V}^{5+}$ or a $\mathrm{V}^{4+}$ species and a second peak at a binding energy of $515.6 \mathrm{eV}$ that can be assigned either to $\mathrm{V}^{4+}$ or $\mathrm{V}^{3+}(\Delta \mathrm{E}=1.6 \mathrm{eV})$ $[31,32]$ (Figure 5). However, these values are closer to those observed in the other samples for the pair $\mathrm{V}^{+4} / \mathrm{V}^{+3}$ than those observed for the pair $\mathrm{V}^{5+} / \mathrm{V}^{4+}$. This may be related to the different experimental procedure as this catalyst was prepared by thermal treatment under $\mathrm{N}_{2}$ flow and Charcoal is also known to have reductive properties. On the other hand, since the total amount of $\mathrm{V}$ detected at the surface in this case is rather small, around $1.6 \mathrm{w} \%$, it is likely that a distribution similar to the one observed in the case of the sample $\mathrm{V} / \mathrm{Y}_{2}-\mathbf{0 . 4}$ is occurring. Besides that, since the most oxidized species are also the smallest ones, they would lie preferably in the bottom of the pores.

The relative amount of $\mathrm{V}$ species present in this sample is $72.7 \%$ for $\mathrm{V}^{4+}$ and $27.3 \%$ for $\mathrm{V}^{3+}$. The values summarized in Table 1 show that the main peak, in all these samples, is that corresponding to $\mathrm{V}^{4+}$ species and that showing the lowest concentration corresponds to the $\mathrm{V}^{3+}$ species. They also show that, for the samples with lower $\mathrm{V}$ loadings, no $\mathrm{V}^{5+}$ species can be observed on the surface.

It is also interesting to note that, while in the case of $V$ samples over zeolite some positive segregation of the $V$ to the surface is observed (the surface concentration of vanadium as determined by XPS is higher than the average concentration as determined by ICP) in the case of the $V$ samples over charcoal this segregation is negative (a lower concentration of $\mathrm{V}$ was determined for the surface by XPS method $(1.6 \mathrm{w} \%)$ than the one determined by ICP $(4 \mathrm{w} \%)$ for the bulk. It seems that in the 
case of the charcoal most part of the $\mathrm{V}$ ions lie deep inside the micro pores and, thus, are not observed by XPS. This effect may be due to the larger diameter of the charcoal pores compared to those of the zeolite $Y(22 \mu$ vs $13 \mu)$. A larger interaction of the zeolite surface with the metal compared to that of the charcoal, may also explain in part why a larger concentration of $V$ is found at the surface in the case of the zeolite sample. The same effects had been observed in the case of $\mathrm{Cr}$ supported catalysts [26].

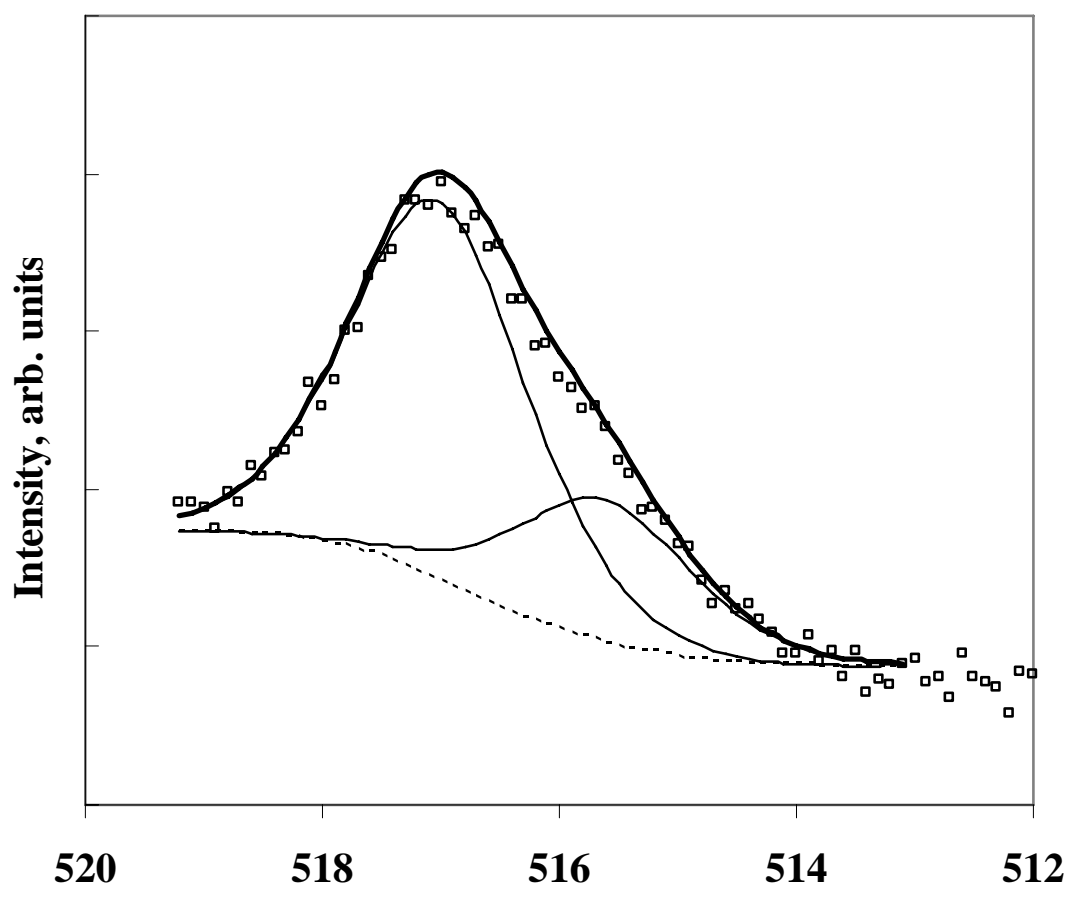

Binding Energy, eV

Fig. 5. XPS spectrum of the sample VIC displaying the $V 2 p_{3 / 2}$ peak. After peak fitting the two peaks can be assigned either to the pair $\mathrm{V}^{5+} / \mathrm{V}^{4+}$ or $\mathrm{V}^{4+} / \mathrm{V}^{3+}$. ( $2 \mathrm{p}_{3 / 2}$ at $517.0 \pm 0.2 \mathrm{eV}$ and $515.6 \pm 0.2 \mathrm{eV})$.

Tab. 1. Binding Energies and Vanadium Concentrations Calculated from XPS Spectra of $V / Y$ and $V / C$ Catalysts

\begin{tabular}{|c|c|c|c|c|}
\hline \multirow[b]{2}{*}{ Sample } & \multicolumn{3}{|c|}{ Oxidation State } & \multirow[b]{2}{*}{$\begin{array}{c}\text { [V]total } \\
(\mathrm{w} \%)\end{array}$} \\
\hline & $\begin{array}{c}\mathrm{V}^{5+} \\
\mathrm{BE} \\
( \pm 0.2 \\
\mathrm{eV})\end{array}$ & $\begin{array}{c}\mathrm{V}^{4+} \\
\mathrm{BE} \\
( \pm 0.2 \\
\mathrm{eV})\end{array}$ & $\begin{array}{c}\mathrm{V}^{3+} \\
\mathrm{BE} \\
( \pm 0.2 \mathrm{eV})\end{array}$ & \\
\hline $\begin{array}{c}\text { V/Y2-0.4 } \\
\text { Relative \% }\end{array}$ & & $\begin{array}{c}516.2 \\
55 \%\end{array}$ & $\begin{array}{c}514.8 \\
45 \% \\
\end{array}$ & 1.1 \\
\hline $\begin{array}{l}\text { V/Y2-2.5 } \\
\text { Relative \% }\end{array}$ & $\begin{array}{r}517.9 \\
21.5 \% \\
\end{array}$ & $\begin{array}{r}516.5 \\
59.8 \% \\
\end{array}$ & $\begin{array}{l}515.1 \\
18.6 \% \\
\end{array}$ & 3.9 \\
\hline $\begin{array}{c}\text { V/Y1-3.1 } \\
\text { Relative \% }\end{array}$ & $\begin{array}{l}518.0 \\
38.5 \% \\
\end{array}$ & $\begin{array}{l}516.5 \\
43.9 \% \\
\end{array}$ & $\begin{array}{l}514.9 \\
17.7 \% \\
\end{array}$ & 5.3 \\
\hline $\begin{array}{c}\text { VIC-4.0 } \\
\text { Relative \% }\end{array}$ & & $\begin{array}{l}517.0 \\
72.7 \%\end{array}$ & $\begin{array}{l}515.6 \\
27.3 \%\end{array}$ & 1.6 \\
\hline
\end{tabular}




\section{Cyclic Voltammetry}

The vanadium catalyst $\mathrm{V} / \mathrm{Y}_{\mathbf{1}} \mathbf{- 3 . 1}$ was also studied in $\mathrm{CV}$. From the results obtained we can also conclude that the fresh catalysts possesses vanadium in various oxidation states; in fact, if the sweep cycle is started, on a fresh pellet, from a positive potential, a significant oxidation current is readily observed indicating the presence of species that are sufficiently reduced to be oxidised at these potentials and if it is started from a negative potential, a significant reduction current is observed (see Figure 6).
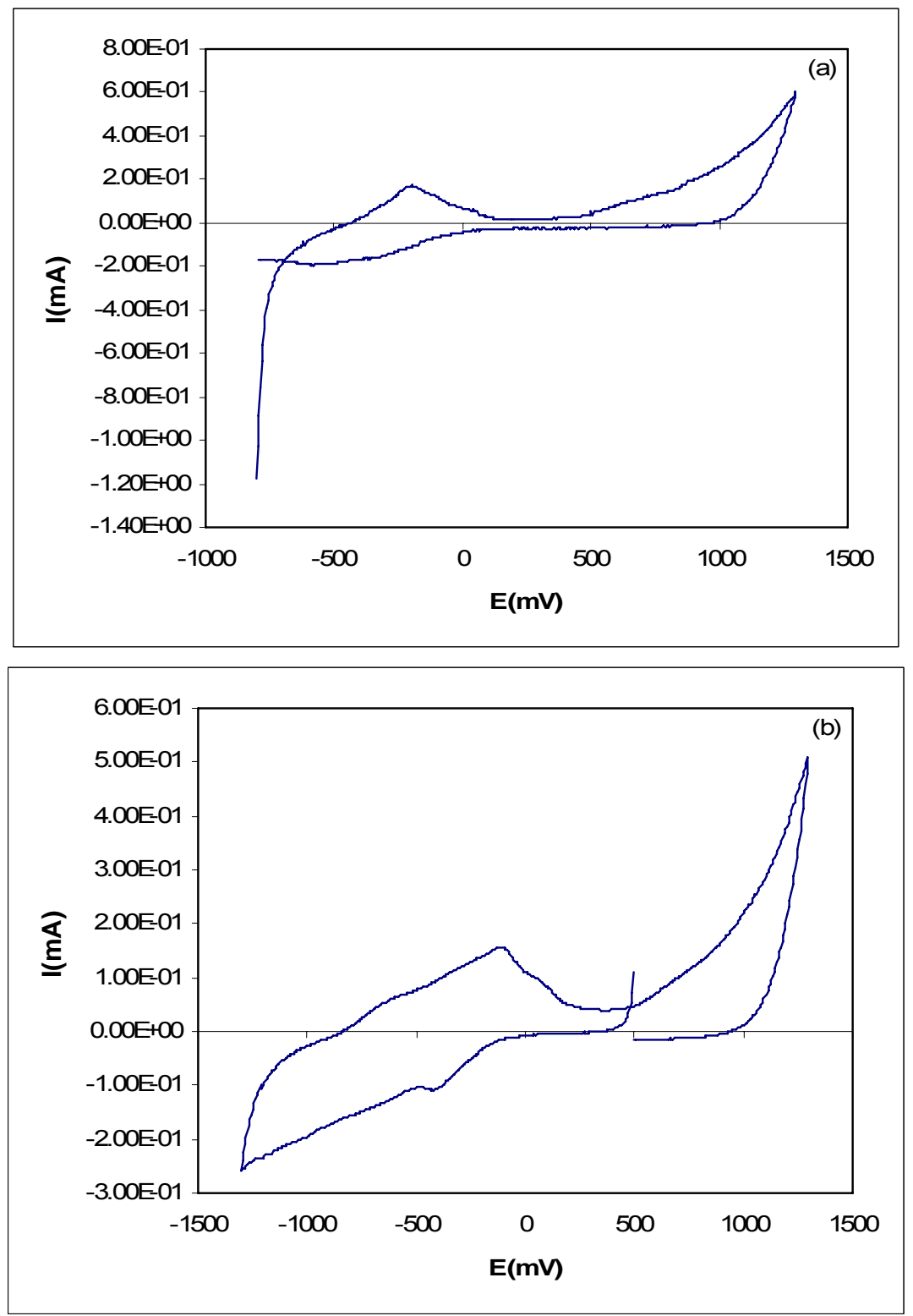

Fig. 6. Cyclic voltammograms of $V / Y_{1}-3.1$ starting either in the positive (a) or negative (b) scan directions, showing that the catalyst contains both oxidised and reduced species. Cyclic voltammograms were obtained at $10 \mathrm{mV} / \mathrm{s}$.

A typical cyclic voltammogram of the electrode with $V / Y_{1-3.1}$ presents two distinct waves, that can be attributed to the $\mathrm{V}^{5+} \mathrm{V}^{4+}$ and $\mathrm{V}^{4+} / \mathrm{V}^{3+}$ redox couples, as it is depicted in Figure 7. 


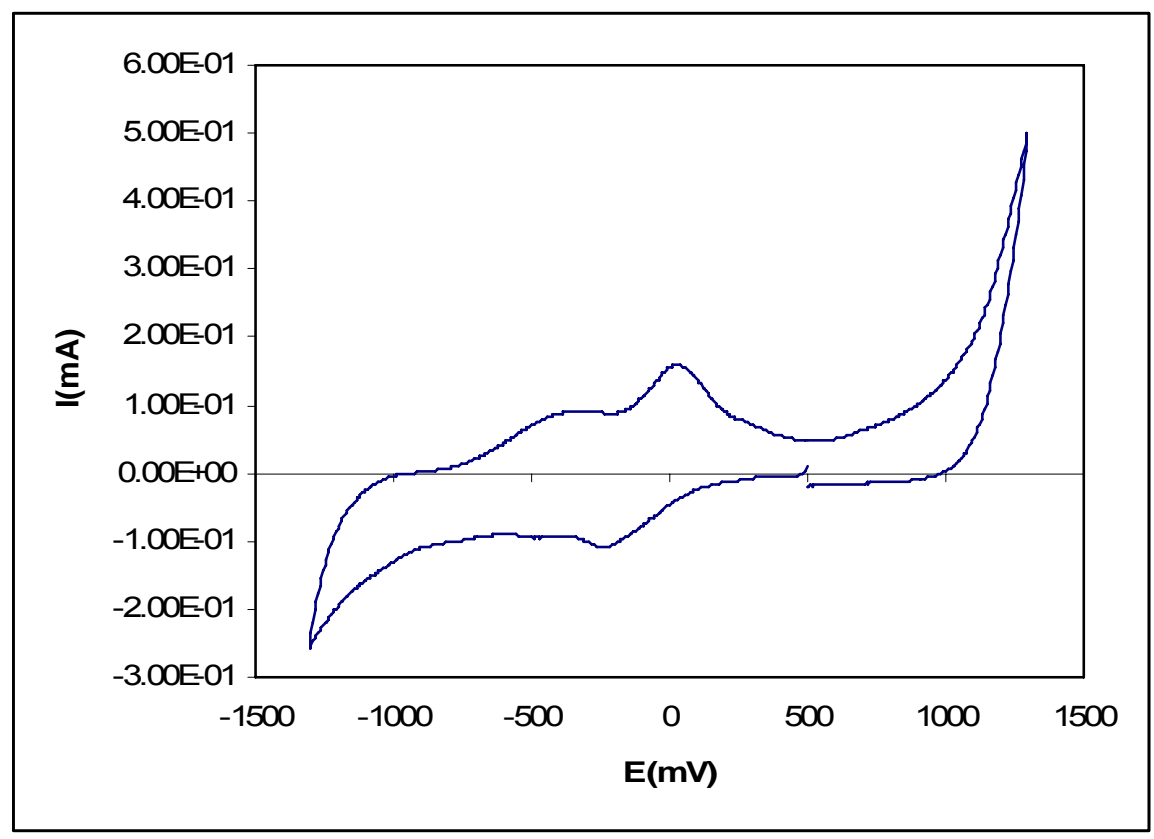

Fig. 7. Cyclic voltammogram of $\mathrm{V} / \mathrm{Y}_{1}-3.1$ presenting two distinct waves, that can be attributed to the $\mathrm{V}^{5+} \mathrm{N}^{4+}$ and $\mathrm{V}^{4+} \mathrm{V}^{3+}$ redox couples. Cyclic Voltammogram was obtained at $10 \mathrm{mV} / \mathrm{s}$ and starting towards more negative potentials.

\section{Partial Conclusion}

The ensemble of characterization results indicates that vanadium, in the calcined samples, appears in a variety of oxidation states, namely as V(IV). This is not unusual and it has been observed by other authors, namely in the study of the solid state reaction between $\mathrm{V}_{2} \mathrm{O}_{5}$ and ZSM-5 by Anpo [34]. The fact that the zeolite seems to stabilize in an oxidation state lower than $V$ for vanadium may be related to the charge distribution in the zeolite framework. In fact, calculating the number of aluminium atoms in a supercage, where the larger vanadium particles that are introduced during the incipient wetness procedure are likely to reside, gives a value close to 4 ; this means that $a+5$ cation would compensate all the framework negative charges in the supercage and an additional one, which would be farther apart. Lower cation charges, like the ones of V(IV) or of the vanadyl species VO2+ (as it was observed by Anpo [34]) result in a closer proximity between the cation and the framework negative charges that it compensates, thus leading to a more stable structure.

\section{Ethylene Polymerization}

The vanadium samples, both supported on zeolite and on charcoal, were used as catalysts in the polymerization of ethylene. No polymer could be obtained in the absence of any alkylaluminum or aluminoxane. The activities obtained when TIBA, TMA, DEAC and MAO were used as scavenger of the medium (or cocatalyst) are shown in Table 2. In this table only the best results obtained for each catalyst system are depicted. Thus the experimental conditions reported are inevitably different from run to run. These results show that, for all the catalyst systems studied, DEAC is the best scavenger (or cocatalyst), the zeolite-based catalysts are slightly better than the charcoal-based ones and the concentration of $\mathrm{V}$ in the catalyst affects the activity of 
the system. The amount of $\mathrm{Na}$ in the support seems not to affect the activity of the catalyst system since similar catalyst performances were obtained when either $\mathrm{NaY}$ or $\mathrm{HY}$ were used as starting material.

Tab. 2. Ethylene Polymerization using V/Y and V/C Catalysts.

\begin{tabular}{|c|c|c|c|}
\hline $\begin{array}{l}\text { Run } \\
\text { No }\end{array}$ & Catalyst & Cocatalyst & $\begin{array}{l}\text { Activity } \times 10^{-3} \\
\text { gPE/molV.h. }[E]^{*}\end{array}$ \\
\hline 80 & $V / Y_{1}-3.1$ & - a) & 0 \\
\hline 81 & $V / Y_{1}-3.1$ & TIBA $^{\text {b) }}$ & 0.53 \\
\hline 82 & $V / Y_{1}-3.1$ & $\mathrm{MAO}^{\mathrm{b})}$ & 0.46 \\
\hline KV33 & $V / Y_{1}-3.1$ & DEAC $^{c)}$ & 10.41 \\
\hline 84 & $V / Y_{1}-3.1$ & $T_{M}{ }^{\text {b) }}$ & 0.08 \\
\hline PV19 & $V / Y_{2}-2.5$ & $D E A C^{d)}$ & 19.6 \\
\hline KV70 & $V / Y_{2}-0.4$ & $\mathrm{DEAC}^{\mathrm{e}}$ & 101.15 \\
\hline 85 & VIC-4.0 & $-f^{\text {f) }}$ & 0 \\
\hline 87 & V/C-4.0 & TIBA $^{\text {g) }}$ & 0.03 \\
\hline KV28 & VIC-4.0 & $\mathrm{MAO}^{\mathrm{n})}$ & 3.38 \\
\hline KV25 & V/C-4.0 & DEAC ${ }^{i)}$ & 5.86 \\
\hline 89 & VIC-4.0 & TMA $^{\text {g) }}$ & 0.71 \\
\hline
\end{tabular}

Experimental conditions: $\mathrm{v}=50 \mathrm{ml}$ toluene; $\mathrm{T}=25^{\circ} \mathrm{C} ; \mathrm{P}=2 \times 10^{5}$ pascal $[\mathrm{E}] \approx 0.37 \mathrm{M} ; \mathrm{t}=60 \mathrm{~min}$ unless otherwise indicated; a) $[\mathrm{V}]=1000 \mu \mathrm{M} ; \quad$ b) $[\mathrm{V}]=430 \mu \mathrm{M}, \quad \mathrm{Al} / \mathrm{V}=300 ; \quad$ c) $[\mathrm{V}]=341 \mu \mathrm{M}, \quad \mathrm{Al} / \mathrm{V}=774 ; \quad$ d) $[V]=283 \mu \mathrm{M}, \quad A \mathrm{I} / \mathrm{V}=600 \mathrm{e})[\mathrm{V}]=530 \mu \mathrm{M}, \quad \mathrm{Al} / \mathrm{V}=67 \mathrm{f})[\mathrm{V}]=800 \mu \mathrm{M} ; \mathrm{g})[\mathrm{V}]=450 \mu \mathrm{M}, \quad \mathrm{Al} / \mathrm{V}=300 ; \mathrm{h}$ ) $[\mathrm{V}]=1000 \mu \mathrm{M}, \mathrm{t}=30 \mathrm{~min}, \mathrm{AI} / \mathrm{V}=300$; i) $[\mathrm{V}]=1000 \mu \mathrm{M}, \mathrm{t}=18 \mathrm{~min}$; Catalyst $\mathrm{V} / \mathrm{Y} 1$ ([V]=2.4-3 \%); Catalyst $\mathrm{V} / \mathrm{Y} 2-2.5([\mathrm{~V}]=2.5 \mathrm{w} \%) ;$ Catalyst $\mathrm{V} / \mathrm{C}([\mathrm{V}]=4 \mathrm{w} \%)$. ${ }^{*}$ Only the organic matter obtained was used for the activity calculations. E concentration determined according to the solubility parameters listed in ASPEN $^{37}$.

The best specific activity, as measured per vanadium atom, was obtained for the catalyst system with a smaller vanadium load, V/Y $\mathbf{Y}_{2}-\mathbf{0 . 4} / \mathrm{DEAC}$ $\left(\mathrm{Ap}=101.5 \times 10^{3} \mathrm{gPE} / \mathrm{molV} . \mathrm{h}\right.$.[E]). The activities of the catalysts $\mathrm{V} / \mathrm{Y}_{\mathbf{1}} \mathbf{- 3 . 1}$ and $\mathrm{V} / \mathrm{Y}_{\mathbf{2}}-\mathbf{2 . 5}$ $\left(\mathrm{Ap}=10 \times 10^{3} \mathrm{gPE} / \mathrm{molV}\right.$.h.[E]) are quite similar and are around ten times lower than observed for the catalyst $V / Y_{2}-0.4$. The activity obtained with the catalyst system VIC-4.0 / DEAC is only slightly lower than those obtained with the zeolite systems of similar $\mathrm{V}$ content $\left(\mathrm{Ap}=5.9 \times 10^{3} \mathrm{gPE} / \mathrm{molV}\right.$.h. $\left.[\mathrm{E}]\right)$ indicating that, in the case of 
vanadium catalysts prepared by the incipient wetness method, charcoal is a support almost as good as the zeolite.

The Differential Scanning Calorimetry (DSC) and Thermal Gravimetric Analysis (TGA) results in Table 3 show that the amount of inorganic matter incorporated in the polymers obtained with different catalyst systems varies between ca $30 \% \mathrm{w} / \mathrm{w}$ (for the catalyst $\mathrm{V} / \mathrm{Y}_{\mathbf{2}}-\mathbf{2 . 5}$ ) and ca $70 \% \mathrm{w} / \mathrm{w}$ (for the catalyst $\mathrm{V} / \mathrm{C}-\mathbf{4 . 0}$ ). These values also show that the presence of inorganic matter affects the heat of fusion and slightly the melting point. The higher the concentration of inorganic matter, the lower the heat of fusion and the melting point of the polymer. It was possible to correlate the values of $\Delta \mathrm{H}_{\mathrm{f}}$ with the amount of inorganic matter in the polymer samples and thus estimate the value of $\Delta \mathrm{H}_{\mathrm{f}}$ for a pure PE sample (with $0 \%$ of inorganic matter). This estimated value, $\Delta \mathrm{H}_{\mathrm{f}}=236.4 \mathrm{~J} / \mathrm{g}$ is close to that referred in literature for a fully crystallized $\mathrm{PE}$ $\left(\Delta \mathrm{H}_{\mathrm{fc}}=291.6 \mathrm{~J} / \mathrm{g}\right)$ [38]. This result and the values obtained for the melting points, $\mathrm{ca}$ $145^{\circ} \mathrm{C}$ suggest that high density PE's are obtained with these vanadium systems.

Tab. 3. Thermal Analysis of the Polymers.

\begin{tabular}{|c|c|c|c|c|}
\hline & \multirow[b]{2}{*}{ Catalyst } & TGA & \multicolumn{2}{|c|}{ DSC } \\
\hline No & & $\begin{array}{c}\text { Inorganic matter } \\
(\%)\end{array}$ & $\begin{array}{l}\Delta \mathrm{H}_{\mathrm{f}} \\
(\mathrm{J} / \mathrm{g})\end{array}$ & $\begin{array}{c}T_{m}(\max ) \\
\left({ }^{\circ} \mathrm{C}\right)\end{array}$ \\
\hline KV34 & $\mathrm{V} / \mathrm{Y}_{1}-3.1$ & 51 & 100 & 132 \\
\hline KV70 & $V / Y_{2}-0.4$ & 39 & 145 & 145 \\
\hline PV19 & $\mathrm{V} / \mathrm{Y}_{2}-2.5$ & 27 & 162 & 144 \\
\hline KV4 & V/C-4.0 & 70 & - & - \\
\hline
\end{tabular}

In the case of chromium catalysts, previously studied [26], similar results were obtained for both $\mathrm{Cr} / \mathrm{Y}$ and $\mathrm{Cr} / \mathrm{C}$ catalysts prepared by the same incipient wetness method, which showed similar activities. Only in the case of zeolite supported catalysts prepared by ion exchange did the activity increase significantly [26, 39]. As discussed in the preparation section, in the case of the $\mathrm{V}$ catalysts the preparation method was restricted to the incipient wetness one, since the ion exchange method cannot be used due to the fact that the vanadium in the precursor $\left(\mathrm{NH}_{4} \mathrm{VO}_{3}\right)$ is part of the anion, not of the cation. In spite of this, the activities obtained with the vanadium catalysts are comparable to those obtained with the $\mathrm{Cr}$ ones having the same amount of metal incorporated $\left(\mathrm{Ap}=101.5 \times 10^{3} \mathrm{gPE} / \mathrm{molV}\right.$.h. $[\mathrm{E}]$ in the case of the $\mathrm{V}$ catalyst, $\mathrm{V} / \mathrm{Y}_{\mathbf{2}} \mathbf{- 0 . 4}$, vs Ap $=104 \times 10^{3} \mathrm{gPE} / \mathrm{molCr}$.h. $[\mathrm{E}]$ in the case of the $\mathrm{Cr}$ one, $\mathrm{Cr} / \mathrm{Y}$ $0.3[26])$. 
The NMR of the polyethylene, depicted in figure 8, shows that, as in the case of $\mathrm{Cr}$ catalysts, the polymer obtained is linear in agreement with the thermal results observed (Table 3).

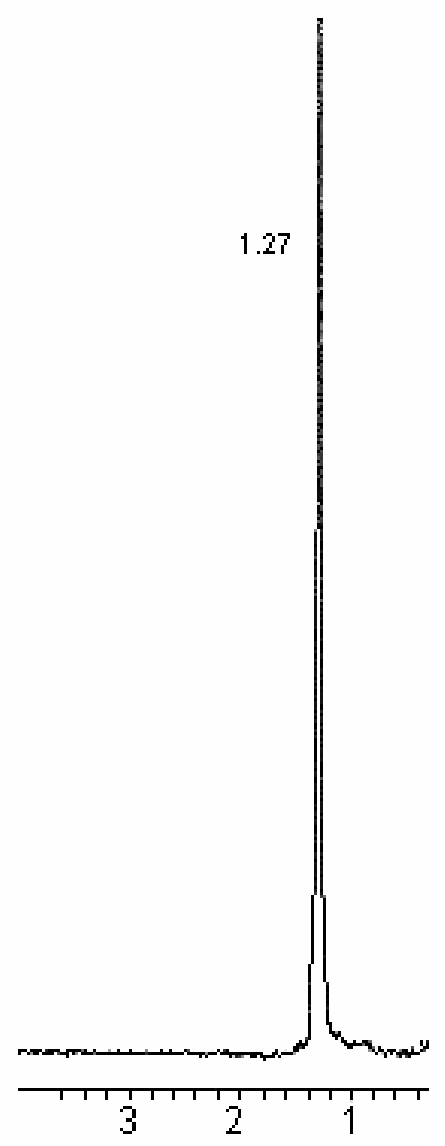

Fig. 8. ${ }^{1} \mathrm{H}$ NMR spectrum of the polyethylene obtained using the $\mathrm{V} / \mathrm{Y}_{2}-2.5 / \mathrm{DEAC}$ catalytic system.

The contamination of these PE samples with zeolite may be inconvenient for some applications but may also bring some benefits. It is known that polyethylene-based composites, including those reinforced with inorganic ceramic particles [19], natural fibres or particles [20, 21], silica nanoparticles [22], glass fibres [23], nanoclay [24] or carbon [25] may have improved mechanic properties when compared to neat PE. Dynamic mechanical analysis (DMA) has been widely used in describing the mechanical performance of those composites.

The PE samples containing about $30 \%$ of incorporated $\mathrm{NaY}$, prepared by using the catalyst system $\mathrm{V} / \mathrm{Y}_{2}-\mathbf{2 . 5}$, were studied by DMA. The results at room temperature are shown in Figure 9, where both $E^{\prime}$ and $\tan \delta$ are displayed as a function of frequency. As expected, the storage modulus increases with frequency for both $\mathrm{PE}$ and zeolite reinforced PE (sample PV 19). The composite material exhibits significant higher values of $E^{\prime}$ as compared with the pure matrix, indicating that the reinforcement result produced by the zeolite fraction is effective; for example, at $1 \mathrm{~Hz}$ the storage modulus are $600 \mathrm{MPa}$ and $1.17 \mathrm{GPa}$ for pure PE and composite films, respectively. No significant changes are found in the loss factor for the two materials: at $1 \mathrm{~Hz} \tan \delta$ varies between 0.08 and 0.1 , indicating that the addition of this content of zeolite does not change the damping properties of polyethylene. 


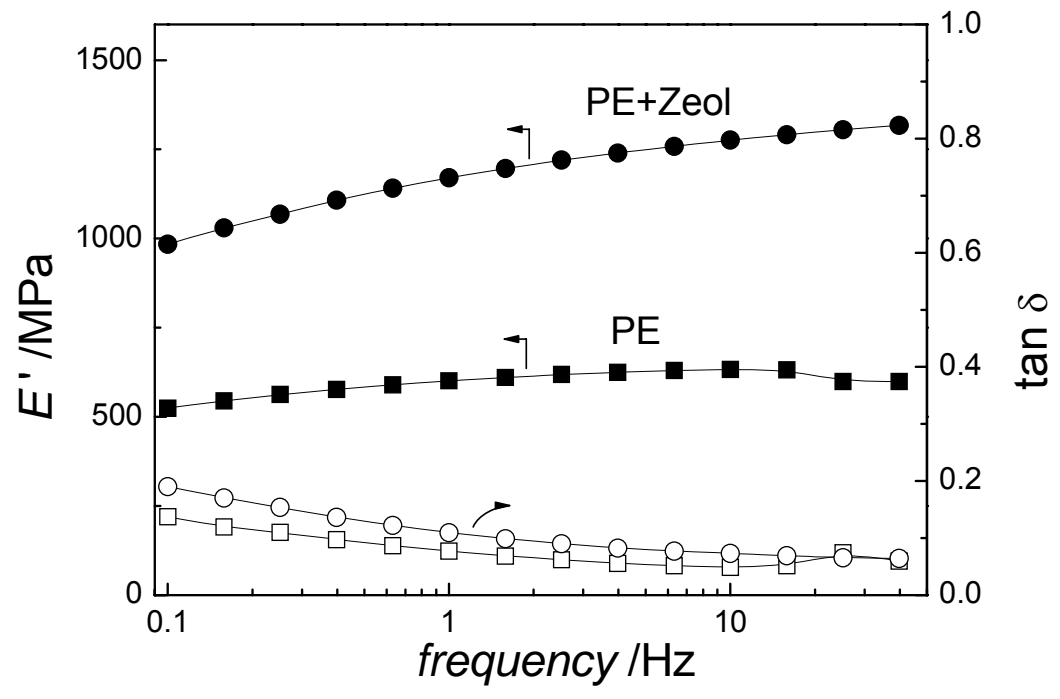

Fig. 9. Dynamic mechanical spectra of PE (squares) and PE/Zeolite blend (circles) recorded at room temperature. Both storage modulus (solid symbols) and loss factor (open symbols) are shown as a function of frequency.

On the other hand it is also known that the presence of microporous materials [40-42] and different zeolites $[43,44]$ including $Y$ zeolite in the PE samples results in a more rapid thermal degradation of the polymer [45]. Since the conventional plastic waste processes (landfill and incineration) is becoming progressively expensive and generates problems due to unacceptable emissions, thermal degradation of polymers may become an interesting alternative [40,46]. However this process requires high temperatures and produces undesirable heavy products. Thus, a method leading to a decrease of the degradation temperature and producing valuable hydrocarbon products would be rather attractive [45].

\section{Kinetic and Modelling Studies}

Although, from the results in this paper and the previous studies with $\mathrm{Cr}$ [26, 39], the latter are, as expected, the most promising ones, $\mathrm{V}$ over zeolite and charcoal is still interesting enough to be studied in more detail from the kinetic point of view.

\section{-Kinetic Model}

The kinetic profiles shown are very similar to those observed for some homogeneous catalyst systems, which also show a decrease of the polymerization rate with time $[47,48]$. The low activity values observed for these catalysts exclude the possibility of diffusion limitations and, so, as for other systems, we can see that, even in the absence of diffusion problems, the polymerization rate may show a decay type profile due to the deactivation of the active sites.

The mechanism proposed is basically described by the following set of equations for the coordination, propagation and deactivation reactions: 


$$
\begin{aligned}
& C_{n}+M \frac{k^{1}}{\leftarrow \frac{k-1}{C}} \rightarrow C_{n} M \\
& C_{n} M-\frac{k_{c_{1}}}{\rightarrow} C_{n+1} \\
& C_{n} M+M \frac{k^{2}}{\leftarrow \frac{k-2}{-}} \rightarrow C_{n} M_{2} \\
& C_{n} M_{2}-\frac{k_{c_{2}}}{\rightarrow} C_{n+1} M \\
& C_{n}-\frac{k d_{1}}{\rightarrow} C_{n}^{d} \\
& C_{n} M-\frac{k d_{2}}{\rightarrow} C_{n} M^{d} \\
& C_{n} M_{2}-\frac{k d_{3}}{\rightarrow} C_{n} M_{2}{ }^{d}
\end{aligned}
$$

Where $C_{n}$ represents an active site with a polymer chain of $n$ monomers, $M$ represents the monomer, $\mathrm{C}_{n} \mathrm{M}$ represents the active site with one molecule of monomer coordinated and $\mathrm{C}_{n} \mathrm{M}_{2}$ the site bearing two coordinated molecules of monomer.

As described in a previous paper [27] a set of differential equations, corresponding to the material balances for all the species involved can be written and integrated.

Each experiment was computed individually, taking into account its particular set of experimental conditions, but using the same set of kinetic parameters. The rate of consumption of ethylene was then compared to the experimental values and the model was, then, fitted to the ensemble of all the experiments for a specific catalyst, for various initial concentrations of catalyst, for various ethylene partial pressures and for different temperatures, so as to obtain a single set of kinetic parameters. The fitting was done using a least-squares approximation, minimizing the sum of the squares of the residuals for all data points in the set of experiments under analysis. Minimization was performed using the Solver tool in Excel.

Estimates for the confidence intervals on the parameters thus computed were obtained by the "bootstrap method" [49]. In this procedure, $1 / 3$ of the original data points were randomly replaced by other data points in the same set and a new optimisation procedure was performed. This procedure was repeated 10 times and the reported set of parameters, along with the respective confidence intervals (for a $95 \%$ confidence level), were computed from the distribution of parameter values obtained.

\section{-Influence of Ethylene Pressure and Reaction Temperature}

Figure 10 through 12 show typical kinetic profiles obtained at different pressures of ethylene for the $\mathrm{V} / \mathrm{Y}_{2}-\mathbf{0 . 4}$ and V/C-4.0 catalysts using DEAC as scavenger. For both catalysts the consumption of ethylene has a maximum followed by a decrease due to the deactivation of the catalyst. This effect is more pronounced for the charcoal supported catalyst. The effect of temperature was also studied for the Zeolite catalyst and the kinetic model fitting was made simultaneously for variations in both pressure and temperature conditions, as depicted through Figure 11. Raising the temperature 
up to $50^{\circ} \mathrm{C}$ corresponds to an increase of the catalytic activity, but when the temperature is further increased up to $80^{\circ} \mathrm{C}$ the global catalytic activity drops.

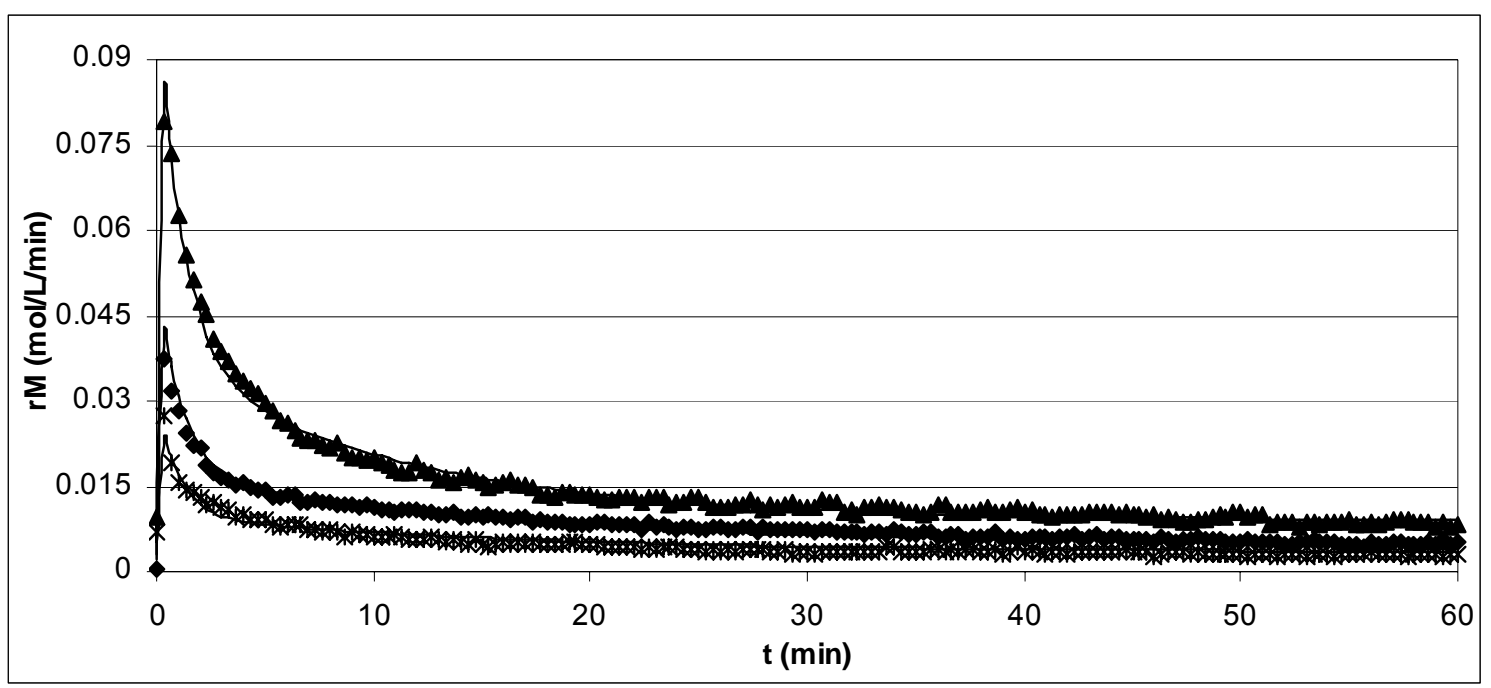

Fig. 10. Consumption of monomer rate versus time for different pressures of ethylene. Experimental conditions: Catalyst $\mathrm{V} / \mathrm{Y}_{2}-0.4 \quad([\mathrm{~V}]=0.4 \mathrm{w} \%)$; Scavenger DEAC; $\mathrm{v}=50 \mathrm{ml}$ toluene; $\mathrm{Al} / \mathrm{V}=100 ; \mathrm{T}=25^{\circ} \mathrm{C} ;[\mathrm{V}]=530 \mu \mathrm{M} ; \bullet \mathrm{P}=2.1 \times 10^{5}$ pascal; * $\mathrm{P}=1.4 \times 10^{5}$ pascal; $\triangle \mathrm{P}=2.9 \times 10^{5}$ pascal . Symbols are experimental data and lines correspond to the kinetic model.

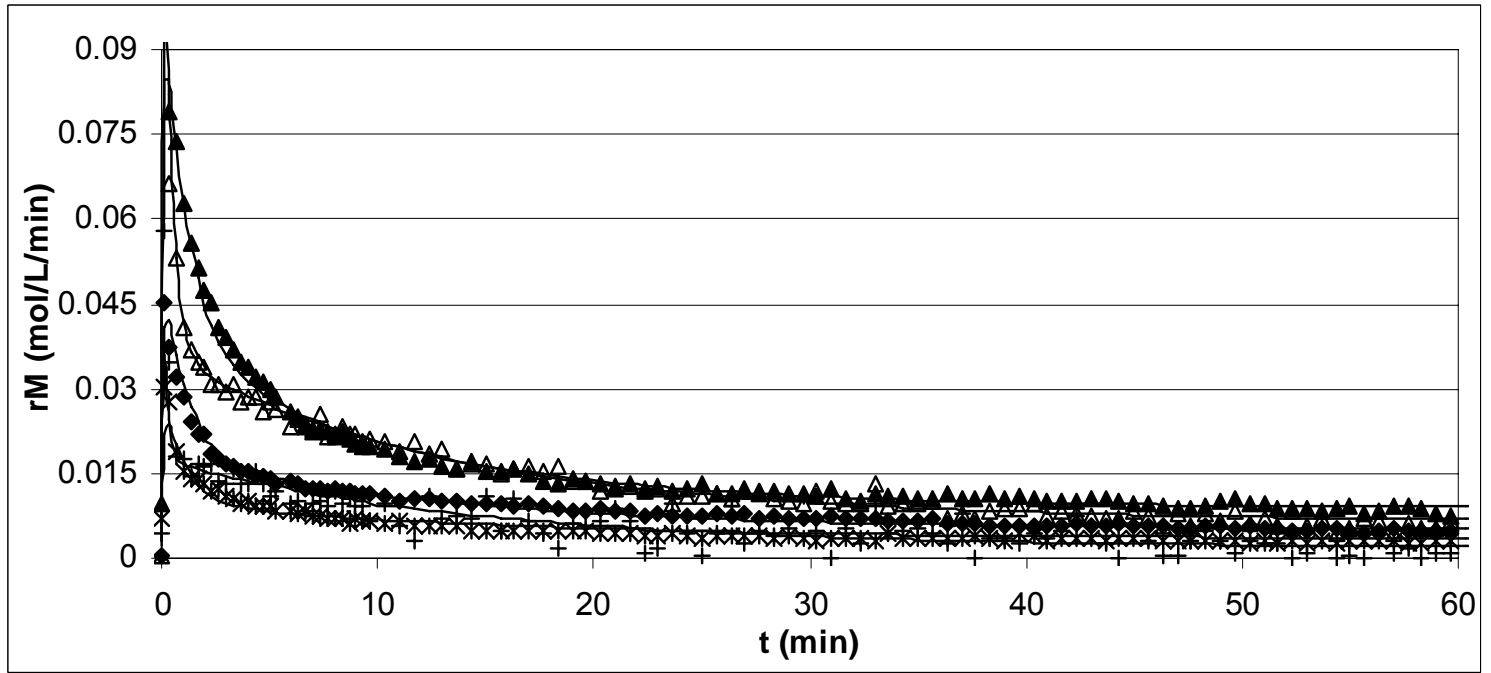

Fig. 11. Consumption of monomer rate versus time for different pressures of ethylene and different temperatures. Experimental conditions: Catalyst $\mathrm{V} / \mathrm{Y}_{\mathbf{2}}-\mathbf{0 4}$ $([\mathrm{V}]=0.4 \mathrm{w} \%)$; Scavenger DEAC; $\mathrm{v}=50 \mathrm{ml}$ toluene; $\mathrm{AI} / \mathrm{V}=100 ; \quad[\mathrm{V}]=530 \mu \mathrm{M} ; *$ $\mathrm{P}=1.4 \times 10^{5}$ pascal; $\mathrm{T}=25^{\circ} \mathrm{C} ; \bullet \mathrm{P}=2.1 \times 10^{5}$ pascal; $\mathrm{T}=25^{\circ} \mathrm{C} ; \Delta \mathrm{P}=2.9 \times 10^{5}$ pascal; $\mathrm{T}=25^{\circ} \mathrm{C} ;+\mathrm{P}=2.1 \times 10^{5}$ pascal, $\mathrm{T}=80^{\circ} \mathrm{C} ; \Delta \mathrm{P}=2.2 \times 10^{5}$ pascal, $\mathrm{T}=50^{\circ} \mathrm{C}$. Symbols represent experimental data and lines correspond to the kinetic model.

The curves in Figure 12, obtained at different ethylene partial pressures for the catalysts system VIC-4.0 - DEAC, show that when the support is the charcoal, a 
faster decrease of the monomer consumption rate along the polymerization time is observed.

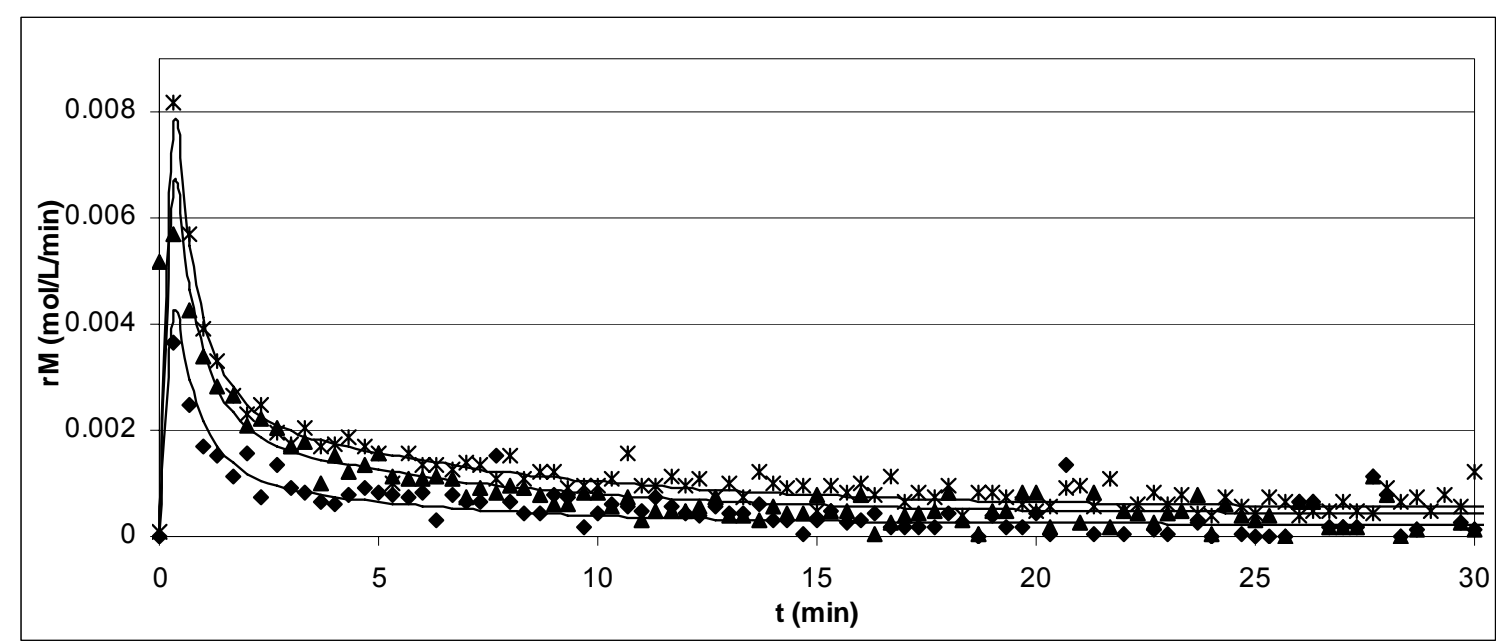

Fig. 12. Consumption of monomer rate versus time for different pressures of ethylene. Experimental conditions: Catalyst VIC-4.0 ([V] $=4 \%)$; Cocatalyst DEAC; $\mathrm{v}=50 \mathrm{ml}$ toluene; $\mathrm{Al} / \mathrm{V}=300 ; \mathrm{T}=25^{\circ} \mathrm{C} ;[\mathrm{V}]=1042 \mu \mathrm{M} ; \bullet \mathrm{P}=1.7 \times 10^{5}$ pascal; $\triangle \mathrm{P}=2.4$ $\times 10^{5}$ pascal; $* \mathrm{P}=2.7 \times 10^{5}$ pascal. Symbols are experimental data and lines correspond to the kinetic model.

In this case, a clear effect of monomer concentration is observed while in the case of the charcoal supported chromium catalyst the partial pressure of ethylene had a very small effect on the reaction rate time profile [26].

Tab. 4. Kinetic rate constants estimated by fitting the model described to the experimental data obtained for the catalyst systems $V / Y_{2}-04 / D E A C$ and $V / C$ 4.0/DEAC.

\begin{tabular}{|c|c|c|c|c|c|c|}
\hline Catalyst & $k_{1}$ & $\mathrm{~K}_{-1}$ & $\mathbf{k}_{\mathrm{c} 1}$ & $k_{2}$ & $\mathrm{~K}_{-2}$ & $\mathrm{k}_{\mathrm{c} 2}$ \\
\hline $\begin{array}{l}\mathrm{V} / \mathrm{Y}\left(25^{\circ} \mathrm{C}\right) \\
\mathrm{Ea}(\mathrm{V} / \mathrm{Y})\end{array}$ & $\begin{array}{l}(2.92 \pm 0.23) \times 10^{-1} \\
(3.51 \pm 0.39) \times 10^{+4}\end{array}$ & $\begin{array}{c}(8.37 \pm 0.32) \times 10^{-2} \\
0\end{array}$ & $\begin{array}{l}(5.19 \pm 0.75) \times 10^{-4} \\
(9.46 \pm 1.63) \times 10^{+1}\end{array}$ & $\begin{array}{c}9.02 \pm 0.23 \\
(4.10 \pm 0.17) \times 10^{+4}\end{array}$ & $\begin{array}{l}(4.11 \pm 0.88) \times 10^{-4} \\
(2.19 \pm 0.04) \times 10^{+5}\end{array}$ & $\begin{array}{c}399 \pm 43 \\
(1.69 \pm 0.22) \times 10^{+2}\end{array}$ \\
\hline $\mathrm{V} / \mathrm{C}\left(25^{\circ} \mathrm{C}\right)$ & $(2.45 \pm 0.09) \times 10^{-3}$ & 0 & 0 & $(2.73 \pm 0.06) \times 10^{+3}$ & $(1.26 \pm 0.05) \times 10^{-4}$ & $125.04 \pm 3.89$ \\
\hline Catalyst & $\mathbf{k}_{1 \mathrm{~d}}$ & $k_{-1 d}$ & $\mathbf{k}_{2 \mathrm{~d}}$ & $k_{-2 d}$ & $\mathbf{k}_{3 d}$ & $k_{-3 d}$ \\
\hline $\begin{array}{l}\mathrm{V} / \mathrm{Y}\left(25^{\circ} \mathrm{C}\right) \\
\mathrm{Ea}(\mathrm{V} / \mathrm{Y})\end{array}$ & $\begin{array}{l}(1.83 \pm 0.14) \times 10^{-2} \\
(7.58 \pm 0.46) \times 10^{+4}\end{array}$ & $\begin{array}{l}(6.23 \pm 0.13) \times 10^{-3} \\
(2.29 \pm 0.13) \times 10^{+4}\end{array}$ & $\begin{array}{c}(4.5 \pm 0.18) \times 10^{-3} \\
(7.12 \pm 0.79) \times 10^{+3}\end{array}$ & $\begin{array}{c}(3.51 \pm 0.07) \times 10^{-4} \\
(3.50 \pm 0.45) \times 10^{+1}\end{array}$ & $\begin{array}{c}(2.88 \pm 0.3) \times 10^{-2} \\
(4.61 \pm 0.13) \times 10^{+4}\end{array}$ & $\begin{array}{c}(5.8 \pm 0.93) \times 10^{-5} \\
(2.81 \pm 0.75) \times 10^{+2}\end{array}$ \\
\hline $\mathrm{V} / \mathrm{C}\left(25^{\circ} \mathrm{C}\right)$ & $(2.52 \pm 0.07) \times 10^{-2}$ & $(4.1 \pm 0.02) \times 10^{-4}$ & $2.57 \pm 0.11$ & 0 & $(5.68 \pm 0.14) \times 10^{-1}$ & $(8.03 \pm 0.34) \times 10^{-3}$ \\
\hline
\end{tabular}

All first order rate constants $\left(\mathrm{k}_{-1}, \mathrm{k}_{\mathrm{c} 1}, \mathrm{k}_{-2}, \mathrm{k}_{\mathrm{c} 2}, \mathrm{k}_{1 \mathrm{~d}}, \mathrm{k}_{-1 \mathrm{~d}}, \mathrm{k}_{2 \mathrm{~d}}, \mathrm{k}_{-2 \mathrm{~d}}, \mathrm{k}_{3 \mathrm{~d}}, \mathrm{k}_{-3 \mathrm{~d}}\right)$ are expressed in $\mathrm{s}^{-1}$, all second order rate constants $\left(\mathrm{k}_{1}, \mathrm{k}_{2}\right)$ are expressed in $\mathrm{s}^{-1} \mathrm{M}^{-1}$ and $\mathrm{Ea}$ are expressed in $\mathrm{J}_{\mathrm{mol}}{ }^{-1}$. Confidence intervals were computed to a $95 \%$ confidence level.

The kinetic parameters obtained by the fitting of this model to the experimental data are shown in Table 4. The values of the kinetic constants show that both the monoand bi-coordinated sites are active in the polymerization of ethylene. However, both the coordination and insertion rates of the bi-coordinated species are much higher $\left(k_{2}=9.02 \mathrm{~s}^{-1} \mathrm{M}^{-1}, \mathrm{k}_{\mathrm{c} 2}=3.98 \times 10^{2} \mathrm{~s}^{-1}\right)$ than those of the mono-coordinated ones $\left(\mathrm{k}_{1}=2.92 \times 10^{-1} \mathrm{~s}^{-1} \mathrm{M}^{-1}, \mathrm{k}_{\mathrm{c} 1}=5.19 \times 10^{-4} \mathrm{~s}^{-1}\right)$ thus showing that a trigger mechanism [50] may be present even in a zeolite supported catalyst. 
The deactivation of this catalyst seems to be temperature dependent with activation energies for the deactivation reactions ranging from $35 \mathrm{~J} / \mathrm{mol}$ to $75.8 \mathrm{KJ} / \mathrm{mol}$, the uncoordinated species $C^{*}$ being the one witch presents the highest activation energy as well as the highest pre-exponential factor. This may explain the decrease of the activity observed when the reaction temperature is raised up to $80^{\circ} \mathrm{C}$.

In the case of the charcoal supported catalyst the kinetic behaviour is described by the same model but a higher second order effect is present since $k_{c 1}$ was fitted to a value indistinguishable from 0 .

\section{Conclusions}

This study shows that $\mathrm{V}$ supported catalysts are active for the polymerization of ethylene and produce composite materials, with the zeolite catalysts embedded inside the polymer that is produced.

Vanadium supported in zeolite has an activity of the order of magnitude of $10^{5}$ and when supported in charcoal they still show activities of the order of $10^{3}$. The $\mathrm{V}$ catalyst supported in zeolite, after 25 minutes reaches a stationary state with an activity of $50 \%$ of the maximum of activity observed (after 8 seconds).

The polyethylene obtained with $\mathrm{V}$ catalysts is practically linear as shown by its ${ }^{1} \mathrm{H}$ NMR spectra and has improved mechanical properties when compared to the pure polymer, due to the inclusion of the zeolite particles.

We may conclude that the $V$ catalysts show activities similar to those observed in the case of the $\mathrm{Cr}$ catalysts [26] and that the zeolite $Y$ was shown to be a better support than charcoal. However, $\mathrm{Cr}$ and $\mathrm{V}$ even when supported in charcoal, showed to be efficient enough as catalysts for the polymerization of ethylene. It is interesting to note that a scavenger has to be used for all the studied metal-supported catalysts. No polymer could be obtained, under the experimental conditions used, in the absence of any alkylaluminum or aluminoxane.

The kinetic study of the vanadium on zeolite catalyst and the modelling based on a proposed mechanism allowed us to clarify some features of this type of catalysts. First, it showed that even an active centre inside the cage of a zeolite (with a cage size of $13 \mathrm{~A}$ ) seems to be able to coordinate two molecules of ethylene. In fact, the best fitting was achieved for the mechanism proposed when the insertion constant for the bi-coordinated species $\mathrm{kc}_{2}$ is seventy thousands higher than that of the monocoordinated species $\mathrm{kc}_{1}$. Secondly, this study showed that for the V/Y catalyst the main deactivation reaction is monomer independent.

\section{Experimental part}

Materials

$\mathrm{NaY}$ zeolite (LZ-Y52, $\mathrm{Na}_{52} \mathrm{Al}_{52} \mathrm{Si}_{140} \mathrm{O}_{384}$ ) was supplied by Union Carbide. Charcoal Activated GR was purchased from Merck (particle size $30 \mu \mathrm{m}, 1 \%$ of ashes, $10 \%$ of humidity, specific area, $S=1081 \mathrm{~m}^{2} / \mathrm{g}$ and total porous volume, $v_{p}=0.67 \mathrm{~cm}^{3} / \mathrm{g}$ ).

$\mathrm{NH}_{4} \mathrm{VO}_{3}$ was purchased from Merck. Trimethylaluminum (TMA), tri-i-butylaluminum (TIBA), and diethylaluminum chloride (DEAC) were all purchased from Aldrich. Methylaluminoxane PMAO-IP with $7 \%$ Al and $1.7 \%$ free TMA, was purchased from Akzo Chemical Company and used as received. 
Ethylene (N25) was supplied by Ar Líquido and passed over a bed of molecular sieves before being used in polymerization.

\section{Catalysts preparation and characterization}

Charcoal was impregnated by the incipient wetness method. The aqueous solutions of the metal salt $\left(\mathrm{NH}_{4} \mathrm{VO}_{3}\right)$, with a metal concentration of $4 \mathrm{w} \%$, were added drop by drop to the charcoal with stirring. The suspension was then evaporated to dryness keeping the stirring to ensure uniformity and catalyst VIC-4.0 was obtained.

Incipient wetness was also used to prepare the vanadium/zeolite catalyst. $\mathrm{NH}_{4} \mathrm{VO}_{3}$ was used since it was not possible to introduce vanadium by ion-exchange with the $\mathrm{Na}^{+}$or $\mathrm{H}^{+}$cations, of $\mathrm{NaY}$ or $\mathrm{HY}$ respectively, as it is usually done with metal cations, and the $\mathrm{V}$ is part of the anion of the salt and not of the cation. It is expected, however, that upon calcination vanadium cations will be formed, as observed by other authors in solid state reactions between vanadium (V) species and zeolites [34].

The solid state reaction may differ when NaY or HY are used as supports. In the case of $\mathrm{NaY}$ the calcination process will lead to the formation of oxides, which can be either from $\mathrm{V}$ or from $\mathrm{Na}$, and that will result in deposits on the support. On the other hand if $\mathrm{HY}$ instead of $\mathrm{NaY}$ is used, and vanadium can replace the protons on the framework, no oxides are expected to remain on the catalyst since the water formed leaves the system during the calcination process.

One $\mathrm{V}$ catalyst with a $\mathrm{V}$ concentration of $3.1 \mathrm{w} \%$ was prepared using $\mathrm{NaY}$ as support $\left(\mathrm{V} / \mathrm{Y}_{1}-\mathbf{3 . 1}\right)$, and two others with concentrations of 0.4 and $2.5 \mathrm{w} \%$ were prepared using $\mathrm{HY}$ as support $\mathrm{V} / \mathrm{Y}_{2}-\mathbf{0 . 4}$ and $\mathrm{V} / \mathrm{Y}_{\mathbf{2}}-\mathbf{2 . 5}$. A better interaction of vanadium with the support is expected in these $V / Y_{2}$ catalysts since the amount of sodium oxides in these samples should be significantly lower than when NaY was used.

$\mathrm{HY}$ was obtained by ion exchange of $\mathrm{NaY}$ with a $2 \mathrm{M}$ aqueous solution of $\mathrm{NH}_{4} \mathrm{NO}_{3}$ performed at $373 \mathrm{~K}$ during 1 hour, followed by calcination at $773 \mathrm{~K}$ under air. The exchange was not complete and the resulting zeolite HY still has $3.8 \mathrm{w} \%$ of sodium as determined by ICP, against the $8.2 \mathrm{w} \%$ of the original NaY zeolite.

In the case of zeolite-based catalysts, the solids obtained after impregnation of the metals were dried at $373 \mathrm{~K}$ overnight and then calcined at $753 \mathrm{~K}$ for 8 hours, under air. The charcoal supported catalysts were also dried at $373 \mathrm{~K}$ over night and then calcined at $753 \mathrm{~K}$ under $\mathrm{N}_{2}$.

The concentration of vanadium incorporated in the zeolite was determined by IPC. Cyclic voltammetry and XPS spectroscopy were used to characterize some of the V catalysts, namely to identify the oxidation state of the metal and to determine its surface concentration. Cyclic voltammograms were obtained using a Radiometer (model DEA 101) digital electrochemical analyzer controlled by a computer, which was also used to acquire the data. The XPS instrument used was a XSAM800 (KRATOS) X-Ray Spectrometer operated in the fixed analyser transmission (FAT) mode, with a pass energy of $20 \mathrm{eV}$ and the non-monochromatised $\mathrm{MgK}_{\alpha} \mathrm{X}$-radiation $(\mathrm{hu}=1253.7 \mathrm{eV})$. Charge effects were corrected using the carbonaceous contamination as reference for binding energies ( $C$ 1s binding energy $=285 \mathrm{eV}$ ). Xray satellite peaks were subtracted. A Shirley background and pseudo-Voigt (Gaussian-Lorentzian products) profiles were fitted using XPSPeak41 software. 
Other experimental details can be found in Part II of this set of papers and references therein [26]. The ESR instrument used was a Bruker SR 300 X-band.

The dynamic mechanical analysis experiments were performed in a TRITEC2000B DMA from Triton Technology (U.K.), using the tensile mode. Both PE and PE/Zeolite blend films were cut into rectangular samples with about $14 \times 4 \times 0.07 \mathrm{~mm}$. The films were fixed between clamps separated by $10 \mathrm{~mm}$ and a pre-load of $1 \mathrm{~N}$ was applied in order to maintain the sample tough. The experiments were carried out by keeping the displacement amplitude constant of $20 \mu \mathrm{m}$ and the frequency was scanned at room temperature (ca. $25^{\circ} \mathrm{C}$ ) between 0.1 and $40 \mathrm{~Hz}$. In each experiment both the elastic modulus $\left(E^{\prime}\right)$ and the loss factor ( $\tan \delta=E^{\prime \prime} / E^{\prime}$, where $E^{\prime \prime}$ is the loss modulus) were recorded against frequency. Each result is the average of three readings.

\section{Polymerization procedure and kinetic measurements}

\section{-Polymerization procedure}

Polymerizations of ethylene were carried out in a flame dried $250 \mathrm{ml}$ crown capped pressure bottle sealed with neoprene septum and pump filled with nitrogen atmosphere after three vacuum/nitrogen cycles. $50 \mathrm{ml}$ of dry toluene were introduced in this polymerization bottle and after evacuating the nitrogen, the reactor is saturated with ethylene at the desired pressure. This pressure was kept nearly-constant throughout the polymerization reactions by using an on/off controller with a dead zone, which opens an inlet valve when the pressure falls below a pre-determined threshold, and closes it again when it exceeds another preset value.

The co-catalyst was added in the proper Al/Ni ratio via a glass syringe. At this time, the solutions were allowed to equilibrate for 5 minutes. After this, the corresponding amount of a catalyst suspension in toluene was added to the polymerization reactors via a glass syringe equipped with a $3 \mathrm{~mm}$ needle. The polymerizations were terminated after the desired time by quenching the mixture with $150 \mathrm{ml}$ of a $1 \%$ $\mathrm{HCl} /$ methanol solution. The obtained polymers were then filtered, washed several times with $50 \mathrm{ml}$ portions of methanol and dried in a vacuum oven at $50^{\circ} \mathrm{C}$ for three days.

Typical kinetic measurements involving the heterogeneous catalysts in a slurry process are made by using an apparatus described previously in more detail [27, 51].

\section{-Polymer Characterization}

${ }^{1} \mathrm{H}$ and ${ }^{13} \mathrm{C}$ NMR spectra were obtained on samples dissolved in a mixture of 1,3,5trichlorobenzene with $10 \% \mathrm{C}_{6} \mathrm{D}_{6}$ at $110{ }^{\circ} \mathrm{C}$. The instrument used was a Varian Unity 300 spectrometer. The internal reference is provided by hexamethyldisiloxane $\left(\delta{ }^{1} \mathrm{H}\right.$ $0.06, \delta{ }^{13} \mathrm{C} 2.0$ relative to tetramethylsilane).

The thermal properties of the polymers were determined by Differential Scanning Calorimetry (DSC). The amount of inorganic matter in the polymerization reaction product was determined by Thermal Gravimetric Analysis (TGA). The equipment used for the DSC/TGA analyses was a SDT 2960 simultaneous DSC/TGA from TA Instruments. The polymers were subjected to a heating ramp between $30^{\circ} \mathrm{C}$ and 200 ${ }^{\circ} \mathrm{C}$ using a heating rate of $10^{\circ} \mathrm{C} / \mathrm{min}$ and a cooling rate less than $10^{\circ} \mathrm{C} / \mathrm{min}$ for $\mathrm{DSC}$ analysis. The TGA analyses of the polymers obtained with zeolite supported catalysts were performed by heating the samples from $30{ }^{\circ} \mathrm{C}$ to $800^{\circ} \mathrm{C}$ in an air stream. In the case of the polymers obtained with charcoal supported catalysts an 
upper temperature of $600^{\circ} \mathrm{C}$ and a nitrogen stream (contaminated with traces of oxygen) were used instead. Several blank runs (only charcoal and V/C catalyst) were carried out in order to get the best conditions for the polymer to be burned leaving almost intact the charcoal (within an error of $\sim 1 \%$ ).

\section{Acknowledgements}

This work was supported in part by Fundação para a Ciência e Tecnologia, and FERDER (Projects POCTI/32775/EQU/99 and POCTI/45104/EQU/2002). Inês Matos (BD/10338/2002) and Yingjun Zhang (BD/15847/98) are grateful to FCT and FSE for their scholarships. We appreciate the support by Borealis for the polymerization equipment.

\section{References}

[1] Hogan, J. P.; Banks R. L. , US Patent 2825 721, March 1958 (filled Aug. 1954).

[2] McDaniel M. P.; Ind. Eng. Chem. Res. 1988, 27, 1559-1564.

[3] McDaniel M.P.; J Catalysis 1981, 67, 71-76.

[4] McDaniel M. P.; J. Catalysis 1982, 76, 17- 28.

[5] McDaniel M. P.; Johnson M. M.; J. Catalysis 1986, 101, 446-457.

[6] Rebenstorf B.; Acta Chem. Scand. 1989, 43, 413-416.

[7] Lunsford J.H.; Fu S-L; Myers D.L.; J. Catalysis 1988, 111, 231-234.

[8] Kim C. S.; Woo S. I.; J. Mol. Catal. 1992, 73, 249-263.

[9] Hartmann M.; Kevan L.; Stud. Surf. Sci. Catal. 1997, 105, 717-724.

[10] Forni L.; Pelozzi M.; Giusti A.; Fornasari G.; Millinit R.; J. Catalysis 1990, 122, 44-54.

[11] Espinoza R. L.; Snel R.; Korf C. J.; Nicolaides C. P.; Appl. Catal. 1987, 29, 295303.

[12] Espinoza R. L.; Korf C. J.; Nicolaides C. P.; Snel R.; Appl. Catal. 1987, 29,175184.

[13] Heveling J.; Van Der Beek A.; De Pender M.; Appl. Catal.1988, 42, 325-336.

[14] Cai T.; Cao D.; Song Z.; Li L.; Appl. Catal. A: General 1993, 95, L1-L7.

[15] Ng F. T. T.; Creaser D. C.; Appl. Catal. A: General 1994, 119, 327-339.

[16] Yashima T.; Ushida Y.; Ebisawa M.; Hara N.; J. Catalysis 1975, 36, 320-326.

[17] Ismayel A.; Sanchez G.; Arribas G.; Ciardelli F.; Materials Eng. 1993, 4, 267-278

[18] Jezequel M.; Dufaud V.; Ruiz- Garcia M. J.; Carrillo-Hermosilla F.; Neugebauer

U.; Niccolai G. P.; Lefebvre F.; Bayard F.; Corker J.; Fiddy S.; Evans J.; Broyer J-P.;

Malinge J.; Basset J-M.; J. Am. Chem. Soc.2001,123, 3520-3540.

[19] Wang M.; Joseph R.; Bonfield W.; Biomaterials 1998, 19, 2357 -2366.

[20] Amash A.; Zugenmaier P.; Polymer 2000, 41, 1589-1596.

[21] Oksman K.; Lindberg H.; J. Appl. Polym. Sci. 1998, 68, 1845-1855.

[22] Huang Y. Q.; Jiang S. L.; Wu L. B.; Polym Testing 2004, 23, 9-15.

[23] Bikiaris D.; Matzinos P.; Prinos J.; Flaris V.; Larena A.; Panayiotou C.; J. Appl.

Polym. Sci. 2001, 80, 2877-2888.

[24] Tanniru M.; Yuan Q.; Misra R. D. K.; Polymer 2006, 47, 2133-2146.

[25] Thongruang W.; Balik C. M.; Spontak R. J.; J. Polym. Sci. Part B-Polym. Phys. 2002, 40, 1013-1025.

[26] Zhang Y.; Matos I.; Lemos MANDA; Freire F.; Nunes T.; Botelho do Rego A. M.; Henriques R. T.; Fonseca I. F.; Marques M. M.; Lemos F.; J. Poym. Sci. Part A: Polym Chem 2003, 41,3768-3780. 
[27] Matos I.; Zhang Y.; Lemos MANDA; Freire F.; Fonseca I. F.; Marques M. M.; Lemos F.; J. Poym. Sci. Part A: Polym Chem 2004, 42, 3464-3472.

[28] Wagner C. D.; Naumkin A. V.; Kraut-Vass A.; Allison J. W.; Powell C. J.; Rumble J. R.; in Jr. NIST X-ray Photoelectron Spectroscopy Database; NIST Standard Reference Database 20, Version 3.4 (web version); http://srdata.nist.gov/xps/ 2003.

[29] Hopfengärtner G, Borgmann D, Rademacher I, Wedler G, Hums E, Spitznagel GW, J Electron Spectrosc Relat Phenom 1993, 63, 91-116.

[30] Abon M.; Bere K. E.; Tuel A.; Delichere P.; J. Catalysis 1995, 156, 28-36.

[31] Delichère P.; Béré K. E.; Abon M.; Appl. Catal. A: General 1998, 172, 295-309.

[32] Nag N. K.; Massoth F. E.; J. Catalysis 1990, 124, 127-132.

[33] Ramoa R. F.; Marcilly Ch.; Rev. I. F. P. 1979, XXXIV, 405-428.

[34] Zhang S. G.; Higashimoto S.; Yamashita H.; Anpo M.; J. Phys. Chem. B 1998, 102, 5590-5594.

[35] Chary K. V. R.; Kishan G.; Kumar C. P.; Sagar G. V.; Appl. Catal. A: General 2003, 246, 335-350.

[36] Casaletto M. P.; Mattogno G.; Massucci M. A.; Appl. Surf. Sci. 2003, 211, 216226.

[37] AspenTech, Aspen Engineering Suite ${ }^{\mathrm{TM}} 10.2$.

[38] Bhajte S. K.; Andrews E. H.; Polym. Eng. Sci. 1983, 23, 888-894.

[39] Zhang Y.; Wang X.; Lemos MANDA; Lemos F.; Henriques R. T.; Marques M. M.; Stud. Surf. Sci. Catal. 2001, 133, 173-180.

[40] Garforth A. A.; Lin Y. H.; Sharratt P. N.; Dwyer J.; Appl. Catal. A: General 1998, 169, 331-342 (1998).

[41] Garforth A. A.; Fiddy S.; Lin Y. H.; Ghanbari-Siakhali A.; Sharratt P. N.; Dwyer J.; Thermochimica Acta 1997, 294, 65-69 (1997) and references there in.

[42] Schirmer J.; Kim J. S.; Klemm E.; J. Anal. Appl. Pyrolysis 2001, 60, 205-217 and references there in.

[43] Gobin K.; Manos G.; Polym. Degrad. Stab. 2004, 83, 267-279.

[44] Gobin K.; Manos G.; Polym. Degrad. Stab. 2004, 86, 225-231 and references there in.

[45] Neves I. C.; Botelho G.; Machado A. V.; Rebelo P.; Europ. Polymer. J. 2006, 42, 1541-1547.

[46] Conesa J. A.; Font R.; Marcilla A.; Garcia A. N.; Energy and Fuels 1994, 8, 1238-1246.

[47] Marques M. M.; Dias A. R.; Costa J.; Lemos F.; Ribeiro F. R.; Polym. Int. 1997, 43, 86-89.

[48] Resconi L.; Fait A.; Piemontesi F.; Colonnesi M.; Rychlicki H.; Zeigler R.; Macromolecules 1995, 28, 6667-6676.

[49] Press W. H.; Teukolsky S. A.; Vetterling W. T.; Flannery B. P.; Numerical Recipes in Fortran - The Art of Scientific Computing, 1992, $2^{\text {nd }}$ Ed. Cambridge: Cambridge University Press, p 684.

[50] Ystens M.; J. Catal. 1991, 129, 383-401.

[51] Correia S.; Lemos F.; Marques M. M.; Ribeiro F. R.; Dias A. R.; $7^{\text {th }}$ International Chemical Engineering Conference CHEMPRO'98, 1998, September 26-28, Lisbon, Portugal. 